\title{
Efeito da adubação potássica na qualidade pós-colheita de maçãs 'Fuji'(1)
}

\author{
Maurício Hunsche ${ }^{(2)}$, Auri Brackmann ${ }^{(3)}$ e Paulo Roberto Ernani(4)
}

Resumo - O objetivo deste trabalho foi avaliar o efeito da adubação potássica na composição mineral, qualidade e armazenabilidade de maçãs da cultivar Fuji. Os frutos utilizados foram provenientes de um experimento em que, durante nove anos, aplicaram-se doses crescentes de $\mathrm{K}_{2} \mathrm{O}$ no solo. As maçãs foram coletadas na safra 1999/2000 e armazenadas em atmosfera controlada (AC) nas condições de $1 \mathrm{kPa} \mathrm{O}_{2} /$ $<0,3 \mathrm{kPa} \mathrm{CO}$ ou $1 \mathrm{kPa} \mathrm{O}_{2} / 2,0 \mathrm{kPa} \mathrm{CO}_{2}$. As avaliações qualitativas foram realizadas na colheita, após oito meses de armazenamento, aos sete dias após a colheita e aos sete dias após oito meses de armazenamento. Nesses sete dias, os frutos permaneceram em temperatura de $20^{\circ} \mathrm{C}$. O incremento no fornecimento de K às plantas aumentou o diâmetro, massa, acidez, coloração vermelha e a concentração de $\mathrm{K}$ nos frutos. Em contrapartida constatou-se diminuições da firmeza da polpa com aumento das doses de potássio. Houve interação entre a adubação e as condições de armazenamento somente em relação à degenerescência de polpa. Não houve diferenças entre os tratamentos quando os frutos foram armazenados em AC de $1 \mathrm{kPa} \mathrm{O}_{2} /<0,3 \mathrm{kPa} \mathrm{CO}_{2}$. Quando as maçãs foram armazenadas em $\mathrm{AC}$ de $1 \mathrm{kPa} \mathrm{O} / 2,0 \mathrm{kPa} \mathrm{CO}$, observou-se maior degenerescência naqueles frutos com menor concentração de potássio. A perda de peso durante o armazenamento, a cor de fundo da epiderme e a ocorrência de podridões não foram afetados pelas doses de potássio.

Termos para indexação: nutriente mineral, armazenamento em atmosfera controlada, distúrbio fisiológico, nutrição vegetal.

\section{Effect of potassium fertilization on the postharvest quality of 'Fuji' apples}

\begin{abstract}
The objective of this study was to evaluate the effects of soil $\mathrm{K}$ fertilization on fruit mineral composition, quality and storability of 'Fuji' apples. Fruits from a long-term trial that evaluated apple response to annual soil applications of $\mathrm{K}_{2} \mathrm{O}$ for nine years were harvested in the 1999/2000 growing season and stored in controlled atmosphere (CA) of $1 \mathrm{kPa} \mathrm{O} / /<0.3 \mathrm{kPa} \mathrm{CO}_{2}$ or $1 \mathrm{kPa} \mathrm{O}_{2} / 2.0 \mathrm{kPa} \mathrm{CO}$. Apples were analyzed for quality and ripening parameters at harvest, after eight months of CA storage, and after seven days at $20^{\circ} \mathrm{C}$ after harvest and after CA storage. The increase on soil $\mathrm{K}$ fertilization raised fruit mass, diameter, titratable acidity, red color, and $\mathrm{K}$ contents while decreased flesh firmness. There was a significant interaction between $\mathrm{K}$ fertilization and storage atmospheres only for internal breakdown: when fruits were stored under $1 \mathrm{kPa} \mathrm{O}_{2} /<0.3 \mathrm{kPa} \mathrm{CO}_{2}$ no differences were determined between treatments. However, storing apples under $1 \mathrm{kPa} \mathrm{O}_{2} / 2.0 \mathrm{kPa} \mathrm{CO}$ resulted in higher breakdown in fruits with lower $\mathrm{K}$ concentrations. Fruit weight losses during storage, ground color and rot incidence were not affected by soil $\mathrm{K}$ fertilization in the previous nine years.
\end{abstract}

Index terms: mineral nutrients, controlled atmosphere storage, physiological disorders, plant nutrition.

(1) Aceito para publicação em 5 de novembro de 2002 . Extraído da dissertação de mestrado apresentada pelo primeiro autor à Universidade Federal de Santa Maria (UFSM), Santa Maria, RS.

(2) Rheinische Friedrich-Wilhelms-Universität Bonn. Auf dem Hügel, 6 D-53121 Bonn, Germany. Bolsista da Capes. E-mail: mhunsche@uni-bonn.de

(3) UFSM, Centro de Ciências Rurais, Dep. de Fitotecnia, CEP 97105-900 Santa Maria, RS. E-mail: brackman@ccr.ufsm.br

(4) Universidade do Estado de Santa Catarina, Dep. de Solos, Caixa Postal 281, CEP 88520-000 Lages, SC. E-mail: prernani@cav.udesc.br

\section{Introdução}

Mais de $45 \%$ da produção nacional de maçãs é constituída pela cultivar 'Fuji'. Nos últimos anos, têm-se realizado esforços para melhorar a qualidade dos frutos comercializados dessa cultivar e assim atender as exigências dos consumidores.

O armazenamento em câmaras com atmosfera controlada tem permitido manter a qualidade dos frutos da cultivar 'Fuji' por oito ou nove meses (Fan, 1992; Jobling \& McGlasson, 1995). Entretanto, a qualidade pós-colheita dos frutos também depende de fato- 
res pré-colheita, como tipo de solo, local de produção, poda, nutrição mineral, entre outros. Com relação à nutrição mineral, atenção especial tem sido dada ao N, Ca, Mg e K, pois são os nutrientes mais relacionados com a qualidade e ocorrência de distúrbios fisiológicos nos frutos (Ferguson et al., 1999).

A adubação potássica afeta o rendimento (Ernani et al., 2002), a composição mineral e o peso (Perring \& Pearson, 1976), a acidez (Fidler et al., 1973; Perring \& Pearson, 1976; Neilsen et al., 1998; Jaeger \& Putter, 1999), a intensidade da coloração vermelha dos frutos (Fidler et al., 1973; Neilsen et al., 1998) e a incidência de danos causados por $\mathrm{CO}_{2}$ em maçãs armazenadas (Wills \& Scott, 1981). Além disso, em muitos pomares brasileiros, os fertilizantes potássicos são aplicados indiscriminadamente (Basso et al., 1990), o que pode afetar a qualidade pós-colheita dos frutos.

O objetivo deste trabalho foi avaliar o efeito da adubação potássica na composição mineral, qualidade e armazenabilidade de maçãs da cultivar Fuji.

\section{Material e Métodos}

Os frutos foram colhidos na safra 1999/2000, de plantas de um experimento em que se avaliou o efeito da adubação potássica na produtividade da macieira (Malus domestica Borkh.), cultivar Fuji. O experimento, localizado em um pomar da Agropecuária SCHIO Ltda., em Vacaria, RS (latitude $28^{\circ} 33^{\prime} 0 " \mathrm{~S}$, longitude $50^{\circ} 57^{\prime} 0^{\prime \prime} \mathrm{W}$, e $955 \mathrm{~m}$ de altitude), foi implantado em 1988, sobre porta-enxerto MM 106, na densidade de 1.234 plantas por hectare.

A partir de 1990 foram aplicadas, anualmente, doses crescentes de K, sobre a superfície do solo, sem incorporação, numa faixa de 2,0 m ao longo da projeção da copa das árvores. Nos três primeiros anos, aplicaram-se 0, 22, 45, 90 e $135 \mathrm{~kg} \mathrm{ha}^{-1}$ de $\mathrm{K}_{2} \mathrm{O}$; de 1993 até 1998 , as doses foram aumentadas, respectivamente, para $0,37,75,150$ e $300 \mathrm{~kg} \mathrm{ha}^{-1}$ de $\mathrm{K}_{2} \mathrm{O}$. No inverno de 1999 , precedendo ao início da safra em que foram colhidos os frutos, não foi aplicado $\mathrm{K}$ em nenhum tratamento. $\mathrm{O}$ delineamento experimental usado foi o de blocos ao acaso, com quatro repetições e cada unidade experimental era constituída por seis plantas seqüienciais na fileira. Anualmente, aplicaram-se na área experimental $40 \mathrm{~kg} \mathrm{ha}^{-1} \mathrm{de} \mathrm{N}$ (uréia). Foram feitas de oito a dez pulverizações foliares com $\mathrm{CaCl}_{2}$ a $0,5 \%$ a partir de 30 dias após a plena floração, e todas as demais práticas agrícolas recomendadas para a cultura.

Em 29/3/2000, foram colhidos os frutos de tamanho médio, nas quatro plantas centrais de cada unidade expe- rimental. A seguir, as maçãs foram transportadas até o Núcleo de Pesquisa em Pós-colheita da Universidade Federal de Santa Maria, Santa Maria, RS, onde foram selecionadas de acordo com uniformidade de tamanho, ausência de defeitos e podridões. Trinta frutos de cada unidade experimental foram submetidos aos tratamentos.

Utilizaram-se duas condições de armazenamento em atmosfera controlada (AC), $1 \mathrm{kPa} \mathrm{O}_{2} /<0,3 \mathrm{kPa} \mathrm{CO}_{2}$ (padrão de AC para maçãs (Fuji') e $1 \mathrm{kPa} \mathrm{O}_{2} / 2 \mathrm{kPa} \mathrm{CO}$, cada uma delas constituindo-se num experimento distinto, e cujos resultados foram analisados conjuntamente.

As maçãs foram armazenadas em minicâmaras de AC, com capacidade de $390 \mathrm{~L}$, equipadas internamente com um microventilador para homogeneização da atmosfera. As minicâmaras foram alojadas dentro de uma câmara frigorífica, com controle da temperatura. A temperatura na polpa do fruto foi mantida em $-0,5 \pm 0,2^{\circ} \mathrm{C}$. A pressão parcial de oxigênio $\left(\mathrm{O}_{2}\right)$ foi ajustada para $1,0 \mathrm{kPa}$, mediante diluição do ar atmosférico pela injeção de nitrogênio. As pressões parciais de $\mathrm{CO}_{2}$ foram de $<0,3 \mathrm{kPa}$ (baixo $\mathrm{CO}_{2}$ ) e $2,0 \mathrm{kPa}$ (alto $\mathrm{CO}_{2}$ ), obtidas mediante injeção deste gás na forma pura. A umidade relativa (UR) permaneceu em aproximadamente $97 \pm 2 \%$ durante todo o período de armazenamento.

$\mathrm{O}$ monitoramento das pressões parciais de $\mathrm{O}_{2}$ e $\mathrm{CO}_{2}$ foi feito várias vezes ao dia, por um equipamento automatizado de análise e correção de gases. Para aumentar a pressão parcial de $\mathrm{O}_{2}$ nas câmaras, o equipamento de controle injeta ar atmosférico. $\mathrm{O}$ excesso de $\mathrm{CO}_{2}$ é removido através do acionamento de um absorvedor de $\mathrm{CO}_{2}$, à base de $\mathrm{KOH}$ a $40 \%$. Na câmara com baixo $\mathrm{CO}_{2}(<0,3 \mathrm{kPa})$, colocou-se cal hidratada, na proporção de $1,0 \mathrm{~kg}$ de cal:15 kg de frutos, que proporcionou a manutenção das baixas pressões parciais de $\mathrm{CO}_{2}$ durante todo o período de armazenamento.

As avaliações dos frutos foram realizadas no dia seguinte à colheita, após oito meses de armazenamento em AC, aos sete dias após a colheita e aos sete dias após os oito meses de armazenamento em AC. Nesses sete dias, que simulam o período de beneficiamento e comercialização (período de prateleira), os frutos ficaram em câmara de climatização, sob temperatura de $20 \pm 0,5^{\circ} \mathrm{C}$ e umidade relativa de $80 \pm 5 \%$.

As maçãs foram avaliadas quanto às seguintes variáveis: composição mineral (K, Ca e Mg), diâmetro, massa e perda de massa dos frutos, cor de fundo e intensidade de coloração vermelha da epiderme, firmeza da polpa, acidez titulável, respiração, produção de etileno, degenerescência interna e incidência de podridões.

Determinou-se a concentração de K, Ca e Mg em amostras de 25 frutos em três das quatro repetições dos tratamentos no campo. As determinações foram efetuadas no 
laboratório de Fertilidade do Solo da Universidade do Estado de Santa Catarina, em Lages, SC. Utilizaram-se subamostras constituídas por duas frações longitudinais triangulares de cada fruto, cortadas de forma radial, incluindo a epiderme. Após serem trituradas, aproximadamente cinco gramas foram digeridas em $5 \mathrm{~mL} \mathrm{de} \mathrm{H}_{2} \mathrm{O}_{2}$ (30 volumes) e $2 \mathrm{~mL}$ de $\mathrm{H}_{2} \mathrm{SO}_{4}$ concentrado ( $36 \mathrm{~N}$ ), em bloco digestor aquecido a $350^{\circ} \mathrm{C}$. $\mathrm{O} \mathrm{K}$ foi determinado por espectroscopia de emissão, o Ca e o Mg por espectroscopia de emissão induzida por plasma (IPC).

O diâmetro dos frutos foi determinado por meio de duas medições na secção transversal de cada fruto. A massa do fruto foi determinada com o auxílio de balança digital. $\mathrm{O}$ porcentual da perda de massa dos frutos foi obtido pela diferença entre a massa inicial e final de cada unidade experimental, no período de armazenamento em AC e no período de armazenamento em AC mais o período de prateleira (sete dias). Firmeza de polpa, acidez titulável, degenerescência interna e podridões foram determinadas conforme Brackmann et al. (2000). Na determinação da firmeza da polpa, usou-se um penetrômetro manual com ponteira de 7,9 mm de diâmetro. Os frutos com podridões não foram aproveitados nas determinações da firmeza da polpa, acidez titulável, respiração e produção de etileno.

A cor de fundo da epiderme foi determinada com um colorímetro eletrônico, com leitura da cor em escala tridimensional $\mathrm{L} * \mathrm{a} * \mathrm{~b} *(\mathrm{CIELAB})$, procedendo-se uma leitura em cada fruto. $\mathrm{O}$ índice de cor de fundo da epiderme foi calculado pela soma dos valores de $\mathrm{a}^{*} \mathrm{e} \mathrm{b}^{*}$. A cor vermelha dos frutos foi determinada visualmente, antes do armazenamento, por meio da comparação com uma escala subjetiva em que 1 representou menos de $40 \%$ da superfície total do fruto coberta por pigmentos vermelhos; 2 representou área pigmentada de $40 \%$ a 70\%; e 3 indicou área pigmentada superior a $70 \%$.

A produção de etileno e a respiração dos frutos foram avaliadas em amostras de 15 frutos de cada unidade experimental, acondicionados em recipientes de vidro de cinco litros. Três horas após o fechamento dos vidros, foram coletadas duas amostras do espaço livre de cada vidro para quantificação do etileno em um cromatógrafo, equipado com coluna Poropak $\mathrm{N}$ e detector de ionização de chama. As temperaturas da coluna, injetor e detector foram $90^{\circ} \mathrm{C}$, $140^{\circ} \mathrm{C}$ e $200^{\circ} \mathrm{C}$, respectivamente. A produção de etileno foi expressa em $\mu \mathrm{L} \mathrm{kg}^{-1} \mathrm{~h}^{-1}$. A seguir foi determinada a pressão parcial de $\mathrm{CO}_{2}$ dentro de cada recipiente, com um analisador eletrônico de gases de fluxo contínuo, e a respiração $\left(\mathrm{CO}_{2}\right)$ dos frutos expressa em $\mathrm{mL} \mathrm{kg}^{-1} \mathrm{~h}^{-1}$. Após estas determinações, os recipientes foram novamente abertos para restabelecer a atmosfera normal e evitar o acúmulo de etileno e $\mathrm{CO}_{2}$.
Os dados referentes a cada parâmetro, antes do armazenamento, foram submetidos à análise de variância e, quando houve diferenças significativas, determinou-se a equação de regressão em relação às doses de $\mathrm{K}_{2} \mathrm{O}$. Os dados referentes a cada parâmetro, após o armazenamento, foram analisados conjuntamente quanto às duas condições de armazenamento. Nos casos em que houve interação significativa entre adubação e condição de armazenamento, determinou-se a equação de regressão adequada para cada condição de armazenamento. Nos casos em que a interação não foi significativa, a equação de regressão foi determinada independentemente da condição de armazenamento. Antes da análise estatística, os dados expressos em porcentual foram transformados pela fórmula arco-seno $((\mathrm{Y}+0,5) / 100)^{0,5}$.

\section{Resultados e Discussão}

A aplicação de $\mathrm{K}$ no solo em quantidades de até $300 \mathrm{~kg} \mathrm{ha}^{-1}$ ano $^{-1}$ de $\mathrm{K}_{2} \mathrm{O}$, durante nove anos consecutivos, elevou a quantidade desse nutriente nos frutos mas não influenciou a concentração de $\mathrm{Ca}$ ou $\mathrm{Mg}$ (Figura 1). Esses resultados não eram esperados, uma vez que a disponibilidade excessiva de $\mathrm{K}$ deveria inibir a absorção de Ca e Mg (Fidler et al., 1973) e, conseqüentemente, diminuir a concentração desses nutrientes nos frutos (Perring \& Pearson, 1976). Resultados similares foram observados nas três colheitas anteriores desse mesmo experimento, ocasiões em que o aumento da dose de $\mathrm{K}$ teve pequeno efeito nos valores de $\mathrm{Ca}$ e nenhuma influência na concentração de $\mathrm{Mg}$ nos frutos (Ernani et al., 2002).

$\mathrm{O}$ diâmetro dos frutos foi linearmente e positivamente correlacionado com as doses de $\mathrm{K}_{2} \mathrm{O}$, enquanto em relação à massa de frutos, o efeito foi quadrático (Figura 1). A não similaridade de resposta para estes dois parâmetros deve ter ocorrido por causa da modificação do formato padrão dos frutos, induzido pela mudança no tamanho de sua secção longitudinal. Segundo Perring \& Pearson (1976) e Stiles (1999), frutos de macieira com maiores concentrações de K tendem a ter maior massa. A deficiência desse nutriente diminui a síntese de carboidratos nas folhas, o que pode limitar o desenvolvimento adequado dos órgãos vegetativos e frutíferos (Marschner, 1995).

Nas duas avaliações efetuadas após o armazenamento, a perda de massa dos frutos não foi influenciada pelos tratamentos (Figura 1). A perda de massa 
verificada durante os oito meses de armazenamento foi de apenas $0,72 \%$ e pode ser atribuída à elevada umidade relativa mantida nas câmaras (>97\%). A perda de massa aumentou para 2,15\% após manutenção dos frutos durante sete dias na temperatura de $20^{\circ} \mathrm{C}$ e umidade relativa de $80 \%$, condições que proporcionaram maior atividade metabólica dos frutos. Conforme Al-Bachir (1994), os frutos menores são os que perdem mais massa, por causa do aumento da relação área/volume, e da quantidade de estômatos e lenticelas.

Em todas as avaliações, o tratamento que não recebeu $\mathrm{K}$ nos últimos nove anos proporcionou frutos com maior firmeza da polpa, que diminuiu com o aumento da dose de K (Figura 2). Os resultados obtidos no presente trabalho foram semelhantes aos constatados por Lysiak \& Pacholak (1999) e podem ser atribuídos à composição mineral e ao tamanho (diâmetro e massa) dos frutos. Frutos menores, em geral, apresentam maior firmeza da polpa por terem maior porcentual do seu volume ocupado com materiais da parede celular, o que lhes proporciona maior densidade e resistência à penetração do êmbolo do penetrômetro (Sams,1999).

Apesar de a adubação das macieiras com elevadas doses de $\mathrm{K}$ ter proporcionado frutos com menor firmeza da polpa, essa menor firmeza pode ser considerada alta, pois os menores valores foram superiores a $70 \mathrm{~N}$, mesmo após oito meses de armazenamento seguidos de sete dias de exposição dos frutos a $20^{\circ} \mathrm{C}$. Além disso, a firmeza da polpa não é um aspecto crítico na determinação da qualidade das maçãs da cultivar Fuji (Jobling \& McGlasson, 1995).

$\mathrm{O}$ aumento da dose de $\mathrm{K}$ aumentou a acidez titulável, em todas as avaliações (Figura 2). Nas determinações efetuadas na colheita ou após a exposição dos frutos por sete dias a $20^{\circ} \mathrm{C}$, a relação entre acidez e doses de $\mathrm{K}$ foi linear e positiva. Esses resultados foram semelhantes aos obtidos por Fidler et al. (1973), Perring \& Pearson (1976), Neilsen et al. (1998) e Jaeger \& Putter (1999). Segundo Mott et al. (1972), citado por Jaeger \& Putter (1999), os ácidos podem ser transportados para dentro do vacúolo da célula, dependendo da necessidade de contrabalançar os cátions ali presentes. Assim, quanto maior a concentração vacuolar de cátions, maior a concentração de ácidos orgânicos, que não estão facilmente acessíveis para quebra durante a respiração.

Comparando-se as curvas de acidez dos frutos nas análises realizadas na colheita ou após oito meses de armazenamento, constata-se maior redução do teor de ácidos em frutos com menores conteúdos
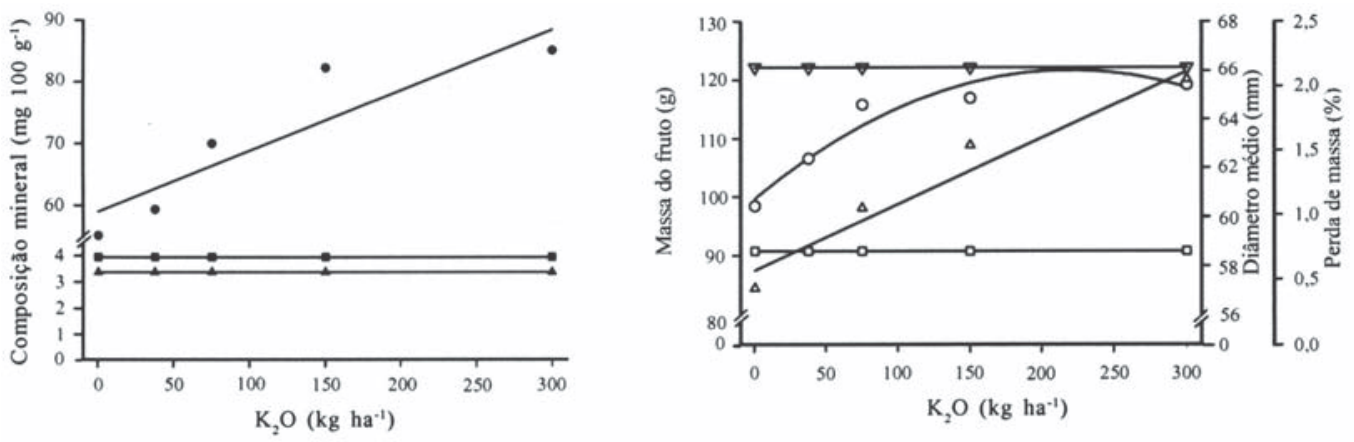

$y(0)=59,00631136+0,98158018 \times \mathrm{R}^{2}=0,808^{\circ}$ $y(O)=99,7200752+0,20093101 x-0,00045814 x^{2} R^{2}=0,93^{\circ}$ $y(\Delta)=57,785+0,02726667 \times R^{2}=0,95^{\circ}$

Figura 1. Efeito de doses de $\mathrm{K}_{2} \mathrm{O}$ aplicadas anualmente sobre a superfície do solo, durante nove anos, no teor de Ca ( $\square$ ), $\operatorname{Mg}(\mathbf{\Delta})$ e $\mathrm{K}(\bullet)$, massa (O), diâmetro (' ) e perda de massa durante o armazenamento em atmosfera controlada ( $\square$ ) e durante o armazenamento + sete dias a $20^{\circ} \mathrm{C}(\square)$, em maçãs da cultivar Fuji. *Significativo a $5 \%$ de probabilidade. Santa Maria, RS, 2000. 
de $\mathrm{K}$, indicando que, possivelmente, estes frutos apresentaram maior taxa metabólica durante o armazenamento.

Independentemente das doses de $\mathrm{K}$ utilizadas, o porcentual de frutos com incidência de podridões não diferiu entre os tratamentos (Figura 3), apesar dos frutos maiores serem menos firmes e, por isso, mais susceptíveis à podridões (Fidler et al., 1973; Al-Bachir, 1994).

A degenerescência da polpa foi o único distúrbio fisiológico observado nos frutos e também foi a única variável em que se determinou interação significativa entre as doses de $\mathrm{K}$ e as condições de armazenamento (Figura 3). No momento de abertura das câmaras, os frutos armazenados sob baixa pressão parcial de $\mathrm{CO}_{2}(<0,3 \mathrm{kPa})$ apresentaram pequeno porcentual da ocorrência do distúrbio, independentemente da dose de $\mathrm{K}$ aplicada no solo. No armazenamento sob elevada pressão parcial de $\mathrm{CO}_{2}(2,0 \mathrm{kPa})$, verificou-se que os frutos menores, e com menor teor de $\mathrm{K}$, foram os que apresentaram maior degenerescência. Após oito meses de armazenamento mais sete dias de exposição dos frutos, não houve interação entre adubação e condição de armazenamento, e as menores doses de $\mathrm{K}$ resultaram em frutos com maior incidência de degenerescência de polpa.

Os frutos maiores normalmente apresentam maior degenerescência de polpa por causa da dificuldade da troca de gases, e do decréscimo na relação área/peso (Al-Bachir, 1994). Segundo Wills \& Scott (1981), quanto maior a relação K/Ca dos frutos, maior sua predisposição para desenvolver degenerescência de polpa. Por outro lado, Lau \& Looney (1982) associaram a maior incidência de danos externos e internos causados por $\mathrm{CO}_{2}$, em maçãs 'Golden Delicious', ao menor teor de $\mathrm{K}$ dos frutos. Os resultados do presente trabalho possivelmente estão mais relacionados com o estado de maturação do que propriamente com o tamanho ou composição mineral dos frutos.

As doses de K não acarretaram diferenças na cor de fundo da epiderme, em nenhuma das avaliações efetuadas (Figura 4). O avanço da maturação diminui a intensidade da coloração verde dos frutos, tornando-a mais amarela, aumentando o índice $\left(a^{*}+b^{*}\right)$, em razão da degradação das clorofilas, por causa da ativação das clorofilases (Ihl et al., 1994).

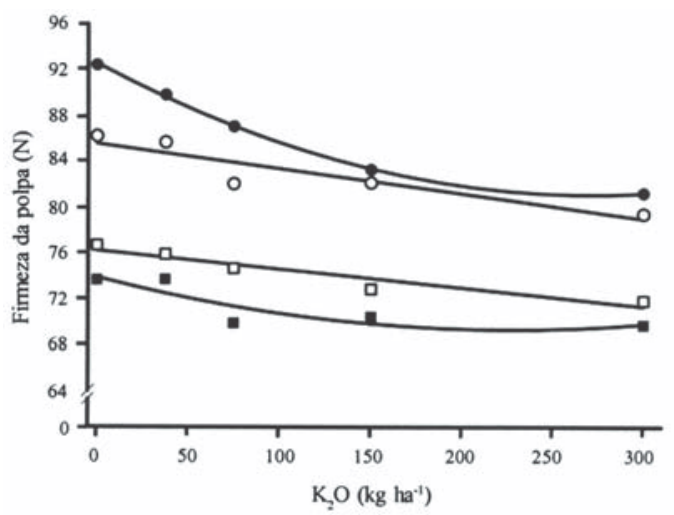

$$
\begin{aligned}
& y(\bullet)=92,53591892-0,08476564 x+0,00015678 x^{2} \quad R^{2}=0,99^{*} \\
& y(O)=85,54277081-0,02186158 x \quad R^{2}=0,84^{*} \\
& y(\square)=73,85029795-0,0451469 x+0,00008948 x^{2} \quad R^{2}=0,76^{*} \\
& y(\square)=76,21420937-0,01639045 x \quad R^{2}=0,91^{*}
\end{aligned}
$$

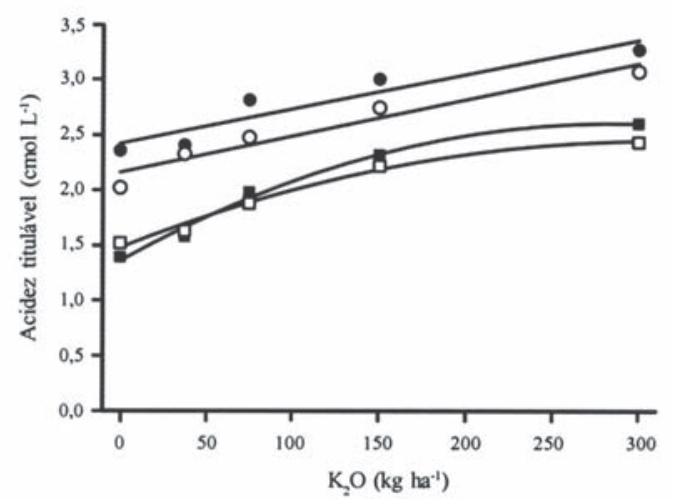

$y(\bullet)=2,425250+0,003140 x \quad R^{2}=0,89 *$ $\mathrm{y}(\mathrm{O})=2,1616125+0,00331 \times \quad \mathrm{R}^{2}=0,94^{*}$

$y(\mathbb{E})=1,35540066+0,0087829 x-0,00001536 x^{2} \quad R^{2}=0,99 *$ $y(\square)=1,47707397+0,00622928 x-0,0000099 x^{2} \quad R^{2}=0,99 *$

Figura 2. Efeito de doses de $\mathrm{K}_{2} \mathrm{O}$ aplicadas anualmente sobre a superfície do solo, durante nove anos, na firmeza de polpa e acidez titulável em maçãs da cultivar Fuji, avaliadas um dia após a colheita $(\bullet)$, um dia após a colheita + sete dias a $20^{\circ} \mathrm{C}(\mathrm{O})$, após oito meses de armazenamento em atmosfera controlada ( $\left.\mathbf{\square}\right)$ e após oito meses de armazenamento em atmosfera controlada + sete dias a $20^{\circ} \mathrm{C}(\square)$. *Significativo a 5\% de probabilidade. Santa Maria, RS, 2000. 
A cor vermelha dos frutos foi afetada positivamente pela aplicação de K no solo (Figura 4). A importância de doses adequadas de K no desenvolvimento da coloração vermelha já havia sido constatada por Fidler et al. (1973) e Neilsen et al. (1998).

Segundo Ju et al. (1999), a síntese de antocianinas em maçãs é dependente da atividade da enzima UDPGalactose:flavonóide-3-o-Glicosiltransferase (UFGalT), e o etileno deve atuar na regulação da expressão do gene desta enzima. No presente trabalho, verificou-se diferenças da coloração vermelha, apesar de não terem sido verificadas diferenças significativas na produção de etileno imediatamente após a colheita e após o armazenamento (Figuras 5 e 6). Possivelmente essa quantidade de etileno foi suficiente a ponto de não limitar a expressão do gene da UFGalT. Ju et al. (1999) também verificaram que a UFGalT é expressa de forma constitutiva na epiderme das cultivares de maçã, inclusive em cultivares não vermelhas e vermelhas que não desenvolvem cor.

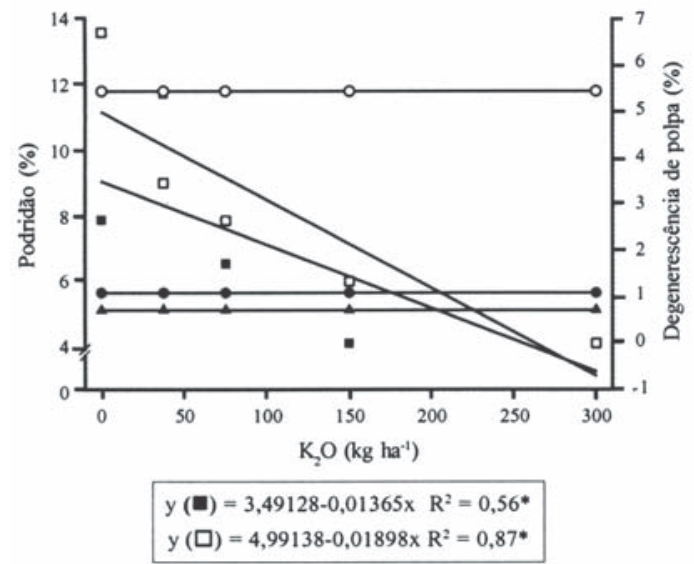

Figura 3. Efeito de doses de $\mathrm{K}_{2} \mathrm{O}$ aplicadas anualmente sobre a superfície do solo, durante nove anos, na incidência de podridões, avaliada após oito meses de armazenamento em atmosfera controlada $(\mathrm{AC}, \bullet)$ e após oito meses de armazenamento em $\mathrm{AC}+$ sete dias a $20^{\circ} \mathrm{C}(\mathrm{O})$ e na degenerescência de polpa avaliada após oito meses de armazenamento em $\mathrm{AC}$, sob pressão de $\mathrm{CO}_{2}$ d $0,3 \mathrm{kPa}$ ( ), após oito meses de armazenamento em $\mathrm{AC}$, sob pressão de $\mathrm{CO}_{2}=2,0 \mathrm{kPa}(\boldsymbol{\square})$ e após oito meses de armazenamento em $\mathrm{AC}+$ sete dias a $20^{\circ} \mathrm{C}(\square)$, em maçãs da cultivar Fuji. *Significativo a $5 \%$ de probabilidade. Santa Maria, RS, 2000.

Pesq. agropec. bras., Brasília, v. 38, n. 4, p. 489-496, abr. 2003
Com base nesses dados, pode-se inferir que o $\mathrm{K}$ tenha papel importante na formação das antocianinas, podendo atuar como co-fator para a atividade de alguma enzima específica desse processo.

Um dia após a colheita, não foram observadas diferenças na respiração dos frutos (Figura 5). Aos quatro dias após a colheita e exposição dos frutos a $20^{\circ} \mathrm{C}$, aqueles com menor teor de $\mathrm{K}$ apresentaram maior taxa respiratória, apesar de não muito elevada. Aos oito dias após a colheita, a taxa de respiração aumentou e continuou maior nos frutos com menor concentração de potássio. Argenta et al. (2000) verificaram que a respiração de maçãs 'Fuji', no início do período de armazenamento, foi de $580 \mu \mathrm{mol} \mathrm{kg} \mathrm{k}^{-1} \mathrm{~h}^{-1}$ (aproximadamente 13,9 $\mathrm{mL} \mathrm{kg}^{-1} \mathrm{~h}^{-1}$ ) e que, durante os oito meses de armazenamento em AC, variou entre 250 e $400 \mu \mathrm{mol} \mathrm{kg}{ }^{-1} \mathrm{~h}^{-1}$. A maior respiração dos frutos com menor teor de $\mathrm{K}$ com objetivo de disponibilizar energia para reparos nos tecidos celulares não pode ser de todo descartada, apesar de nesse momento de avaliação ainda não haver indícios visíveis de distúrbios fisiológicos. É provável que as diferenças observadas sejam decorrentes do diferenciado estado de maturação dos frutos.

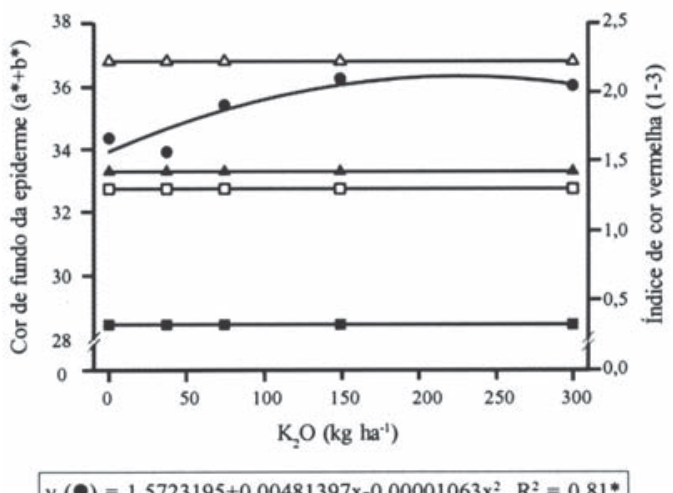

$y(\bullet)=1,5723195+0,00481397 x-0,00001063 x^{2} \quad R^{2}=0,81^{*}$

Figura 4. Efeito de doses de $\mathrm{K}_{2} \mathrm{O}$ aplicadas anualmente sobre a superfície do solo, durante nove anos, na cor de fundo da epiderme, avaliada um dia após a colheita (ם), um dia após a colheita + sete dias a $20^{\circ} \mathrm{C}(\square)$, após oito meses em armazenamento em atmosfera controlada (AC, $\boldsymbol{\Delta})$ e após oito meses de armazenamento em $\mathrm{AC}+$ sete dias a $20^{\circ} \mathrm{C}$ (' ) e índice de cor vermelha (•), em maçãs da cultivar Fuji. *Significativo a 5\% de probabilidade. Santa Maria, RS, 2000 
De forma semelhante à respiração, a produção de etileno após a colheita, seguida de exposição dos frutos por um e quatro dias a $20^{\circ} \mathrm{C}$, não foi influenciada pelas doses de potássio (Figura 5). Nestas épocas, as taxas de produção foram muito pequenas $\left(<0,1 \mu \mathrm{L} \mathrm{L}^{-1}\right)$. Após oito dias de exposição, entretanto, foram verificadas diferenças entre as doses de potássio. Do primeiro para o oitavo dia, a produção de etileno aumentou em mais de 100 vezes, nos frutos oriundos do tratamento que não recebeu $\mathrm{K}$ nos últimos nove anos; nos frutos oriundos dos demais tratamentos também houve aumento significativo da produção de etileno, bem inferior ao tratamento que não recebeu potássio. Nesta avaliação, os frutos com menor concentração de $\mathrm{K}$ apresentaram maior produção de etileno, e a curva de regressão foi muito semelhante àquela obtida em relação à produção de $\mathrm{CO}_{2}$, na mesma avaliação. Estes resultados diferem dos obtidos por Marcelle (1991), que constatou que os frutos com menor relação K/Ca apresentam menor síntese de etileno, devido às menores taxas de seu precursor imediato 1-amino ciclopropano 1-ácido carboxílico.

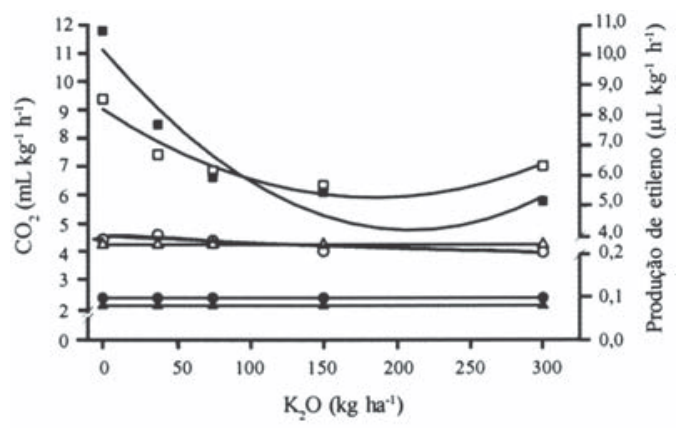

$$
\begin{aligned}
& y(O)=4,51904841-0,00195099 x R^{2}=0,75^{\circ} \\
& y(\square)=9,0591435-0,0337136 x+0,0000908 x^{2} R^{2}=0,91^{\circ} \\
& y(\square)=10,219541-0,057091 x+0,0001359 x^{2} R^{2}=0,92^{\circ}
\end{aligned}
$$

Figura 5. Efeito de doses de $\mathrm{K}_{2} \mathrm{O}$ aplicadas anualmente sobre a superfície do solo, durante nove anos, na respiração com um dia (' ), quatro dias $(\bigcirc)$ e oito dias $(\square)$ após a colheita e na produção de etileno com um dia $(\boldsymbol{\Delta})$, qua-

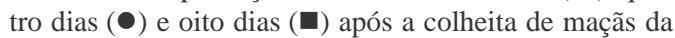
cultivar Fuji. *Significativo a 5\% de probabilidade. Santa Maria, RS, 2000.
A respiração dos frutos, por ocasião da abertura das câmaras de armazenamento, não foi influenciada pela adubação potássica (Figura 6). Após a exposição dos frutos por três e seis dias a $20^{\circ} \mathrm{C}$, verificou-se diferenças entre os tratamentos, e os frutos com menor concentração de K novamente apresentaram maior taxa respiratória. Os níveis de produção de etileno, entretanto, não foram influenciados pelas doses de $\mathrm{K}$, em nenhuma avaliação após o armazenamento. Acreditase que os resultados da respiração e produção de etileno não foram uma conseqüência direta da concentração de $\mathrm{K}$ dos frutos, mas sim, da diferença de maturação na colheita, induzida pelas doses desse nutriente. A antecipação da maturação decorrente da adubação com pequenas doses de K é também a responsável pelo maior desenvolvimento de degenerescência de polpa quando os frutos foram armazenados sob elevada pressão parcial de $\mathrm{CO}_{2}$ e, após a abertura das câmaras e restabelecimento do metabolismo sob elevada temperatura.

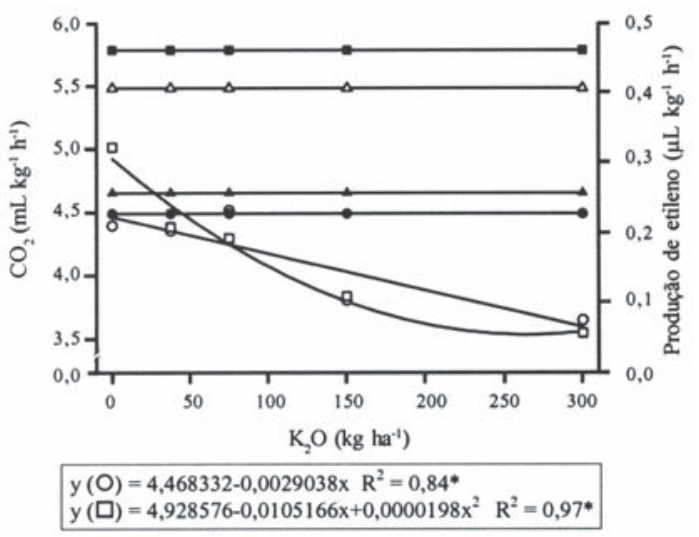

Figura 6. Efeito de doses de $\mathrm{K}_{2} \mathrm{O}$ aplicadas anualmente sobre a superfície do solo, durante nove anos, na respiração avaliada aos oito meses de armazenamento em atmosfera controlada (AC, ' ), aos oito meses em $\mathrm{AC}+$ três dias a $20^{\circ} \mathrm{C}(\mathrm{O})$ e aos oito meses em $\mathrm{AC}+$ seis dias a $20^{\circ} \mathrm{C}(\square)$ e na produção de etileno após oito meses de armazenamento em $\mathrm{AC}(\boldsymbol{\Lambda})$, após oito meses de armazenamento em $\mathrm{AC}+$ três dias a $20^{\circ} \mathrm{C}(\bullet)$ e após oito meses de armazenamento em $\mathrm{AC}+$ seis dias a $20^{\circ} \mathrm{C}(\boldsymbol{\square})$, de maçãs da cultivar Fuji. *Significativo a 5\% de probabilidade. Santa Maria, RS, 2000.

Pesq. agropec. bras., Brasília, v. 38, n. 4, p. 489-496, abr. 2003 


\section{Conclusões}

1. Adubações com doses crescentes de $\mathrm{K}$ em macieiras da cultivar Fuji proporcionam aumentos crescentes dos teores de $\mathrm{K}$ nas maçãs.

2. A deficiência de $K$ no solo resulta em frutos pequenos, mais firmes, com menor teor de ácidos e menor coloração vermelha na colheita em comparação aos frutos oriundos de plantas bem supridas de potássio.

3. Os frutos com menor teor de $\mathrm{K}$ apresentam maior incidência de degenerescência da polpa, principalmente quando armazenados sob $2 \mathrm{kPa}$ de $\mathrm{CO}_{2}$.

\section{Referências}

AL-BACHIR, M. Effect of variety and fruit size on storability of apples. Acta Horticulturae, Leuven, n. 368 , p. 698-705, 1994.

ARGENTA, L. C.; FAN, X.; MATTHEIS, J. Delaying establishment of controlled atmosphere or $\mathrm{CO}_{2}$ exposure reduces 'Fuji' apple $\mathrm{CO}_{2}$ injury without excessive fruit quality loss. Postharvest Biology and Technology, Amsterdam, v. 20, p. 221-229, 2000.

BASSO, C.; WILMS, F. W. W.; STUKER, H. Soil-plant-fruit nutritional relationship in apple orchards in southern Brazil. Acta Horticulturae, Leuven, n. 274, p. 33-42, 1990.

BRACKMANN, A.; HUNSCHE, M.; STEFFENS, C. A. Conservação da maçã 'Fuji' sob diferentes temperaturas, umidades relativas e momentos de instalação da atmosfera de armazenamento. Ciência Rural, Santa Maria, v. 30, n. 1, p. $81-84,2000$.

ERNANI, P. R.; DIAS, J.; FLORE, J. A. Annual additions of potassium to the soil increased apple yield in Brazil. Communications in Soil Science and Plant Analysis, Athens, Estados Unidos, v. 33, n. 7/8, p. 1291-1304, 2002.

FAN, X. Maturity and storage of 'Fuji' apples. 1992. 201 leaves. Dissertation (Master Science in Horticulture) - Washington State University, Pullman, 1992.

FERGUSON, I. B.; VOLZ, R.; WOLF, A. Preharvest factors affecting physiological disorders of fruit. Postharvest Biology and Technology, Amsterdam, v. 15, p. 255-262, 1999.

FIDLER, J. C.; WILKINSON, B. G.; SHARPLES, R. O. The biology of apple and pear storage. Maidstone: Commonwealth Agricultural Bureaux, 1973. 235 p.

IHL, M.; ETCHEBERRIGARAY, C.; BIFANI, V Chlorophyllase behavior on 'Granny Smith' apples. Acta Horticulturae, Leuven, n. 368, p. 59-68, 1994.

Pesq. agropec. bras., Brasília, v. 38, n. 4, p. 489-496, abr. 2003
JAEGER, A.; PUTTER, H. Preharvest factors and postharvest quality decline of apples. Acta Horticulturae, Leuven, n. 485, p. 103-110, 1999.

JOBLING, J. J.; McGLASSON, W. B. A comparison of ethylene production, maturity and controlled atmosphere storage life of 'Gala', 'Fuji' and 'Lady Williams' apples (Malus domestica Borkh.). Postharvest Biology and Technology, Amsterdam, v. 6, p. 209-218, 1995.

JU, Z.; DUAN, Y.; JU, Z. Effects of covering the orchard floor with reflecting films on pigment accumulation and fruit coloration in 'Fuji' apples. Scientia Horticulturae, Amsterdam, v. 82, p. 47-56, 1999.

LAU, O. L.; LOONEY, N. E. Improvement of fruit firmness and acidity in controlled-atmosphere-stored 'Golden Delicious' apples by rapid $\mathrm{O}_{2}$ reduction procedure. Journal of the American Society for Horticultural Science, Alexandria, v. 107, n. 4, p. 531-534, 1982.

LYSIAK, G. P.; PACHOLAK, E. Effects of 13 years soil fertilization on storage quality of 'Cortland' apples. Acta Horticulturae, Leuven, n. 485, p. 265-271, 1999.

MARCELLE, R. D. Relationships between mineral content, lipoxygenase activity, levels of 1-aminocyclopropano-carboxylic acid and ethylene emission in apple fresh disks (cv. Jonagold) during storage. Postharvest Biology and Technology, Amsterdam, v. 1, n. 2, p. 101-109, 1991.

MARSCHNER, H. Mineral nutrition of higher plants. London: Academic, 1995. 889 p.

NEILSEN, G. H.; PARCHORNCHUK, P.; MEHERIUK, M.; NEILSEN, D. Development and correction of K deficiency in drip irrigated apple. HortScience, Alexandria, v. 33, n. 2, p. 258-261, 1998.

PERRING, M. A.; PEARSON, K. Residual effects of fertilizers and orchard management. In: WILKINSON, B. G. (Ed.). Fruit storage. Maidstone: East Malling Research Station, 1976. p. 71-84.

SAMS, C. E. Preharvest factors affecting postharvest texture. Postharvest Biology and Technology, Amsterdam, v. 15, p. 249-254, 1999.

STILES, W. C. Effects of nutritional factors on regular cropping of apple. HortTechnology, Alexandria, v. 9, n. 3, p. 328-331, 1999.

WILLS, R. B. H.; SCOTT, K. J. Studies on the relationship between minerals and the development of storage breakdown in apples. Australian Journal of Agricultural Research, Melbourne, v. 32, p. 331-338, 1981. 